\section{Mostrando y ocultando Nueva York: cine, cultura y realidad en los dorados veinte}

Alberto Lena *

Resumen: En este trabajo se busca comprender la importancia que adquiere Nueva York como paradigma de la ciudad moderna en los años veinte por medio del análisis de una serie de películas rodadas en esa ciudad durante los años veinte, entre las que destacan obras como The Crowd de King Vidor, Speedy de Ted Wilde y Lonesome de Paul Fejos. En esta investigación tratará de descubrir cómo el cine clásico de Hollywood trató de hacer frente a los retos de la modernidad construyendo una imagen positiva del ciudadano medio, un ciudadano capaz de sobrevivir en un contexto dominado por la cultura de masas.

Palabras clave: John Dos Passos - Paul Fejos - F.S. Fitzgerald - Harold Lloyd - King Vidor [Resúmenes en inglés y portugués en las páginas 104 - 105]

${ }^{(*)}$ Doctor en Filología Inglesa por la Exeter University y en Teoría, Análisis y Documentación Cinematográfica por la Universidad de Valladolid. Miembro del Departamento de Humanidades de la Universidad Isabel I y funcionario de la Junta de Castilla y León. Ha publicado diferentes artículos en libros y revistas especializadas.

\title{
Introducción
}

A partir de los años veinte, Nueva York se transformó, de repente, en la metrópolis por excelencia que encarnaba los ideales de la modernidad: la velocidad, el culto por la novedad incesante, la cultura de masas y el poder de la técnica. La enorme y deslumbrante metrópolis, con sus rascacielos y multiplicaciones, inspiró las obras de diferentes artistas en esa época, entre los que destacan, escritores como John Dos Passos y Francis Scott Fitzgerald, y cineastas como Paul Fejos, Harold Lloyd y King Vidor. La ciudad, con sus enormes rascacielos y aceleradas multitudes, se convirtió en el emblema de una nueva estética literaria y visual que requería una nueva técnica literaria y cinematográfica para poder ser representada con todos sus contrastes. Como ha señalado Malcolm Bradbury, el modernismo como movimiento estético no se puede comprender sin la aparición de las grandes ciudades a principios del siglo XX (p.97). 
No es mera casualidad que, a partir del fin de la Primera Guerra Mundial, Nueva York lograra eclipsar, en la imaginación popular, a otras metrópolis como Berlín, París y Londres que desempeñaron también un papel enorme en esos años. Las trasformaciones de Nueva York eran un reflejo de los cambios políticos que había sufrido la sociedad occidental y la norteamericana tras el estallido de la catástrofe bélica. Sin lugar a dudas, la sociedad norteamericana se vio obligada a abandonar su provincialismo, debido a la intervención en la contienda y a ser consciente de su importancia geopolítica a nivel mundial. Sin embargo, la destrucción económica y social, a la que se vio sometida Europa tras la guerra, convirtieron a la sociedad norteamericana en un referente mundial. Los Estados Unidos ya no tenían que mirar a Europa para encontrar modelos culturales. Esto se pudo apreciar, especialmente, en la industria cinematográfica. Tras la guerra, las películas francesas e italianas dejaron de exportarse como lo habían hecho antes de la contienda, debido a la grave crisis económica de esos años y a las interrupciones ocasionadas, a la hora de rodar películas, por los enfrentamientos bélicos. Estados Unidos cubrió ese vacío, y Hollywood acabó apoderándose del mercado mundial: el único referente de la cultura de masas.

El final de la guerra coincidió con el enorme desarrollo de los núcleos urbanos en los Estados Unidos. El cine, la publicidad y luego la radio invadieron todas las pequeñas localidades del país. Los jóvenes comenzaron a imitar los vestidos y los peinados de las estrellas de Hollywood, y la sociedad norteamericana, que hasta entonces había imitado muchos de los hábitos de la cultura inglesa victoriana, comenzó a liberalizarse de forma acelerada. Nueva York era el lugar que simbolizaba ese cambio. A ella acudían millones de hombres y mujeres anónimos para formar parte del enorme engranaje de la modernidad que nacía en sus calles. La película Manhatta (1921) dirigida por Paul Strand y Charles Wheeler representó uno de los primeros homenajes al dinamismo estético de la gran metrópolis. Strand y Wheeler transformaron en algo sublime las imágenes de los edificios que se extendían a lo largo de las abigarradas arterias urbanas de la isla. En ese universo de vértigo y asfalto los individuos se convierten en meras hormigas, en seres accidentales. La velocidad de la técnica, el poder del capitalismo y el frenesí de las multitudes humanas constituyen la imagen de la modernidad para estos autores.

Strand y Wheeler, con su estética vertiginosa que se adaptaba a los continuos cambios del paisaje urbano, mostraban un mundo en continua transformación, en el que los seres humanos ya no podían controlar la realidad más inmediata de la que se nutría su existir diario. Nueva York, con su enormidad y sus ritmos de trabajo y de ocio, anunciaba el fin de toda una cultura norteamericana que había identificado el desarrollo del país con la expansión de la frontera. En el siglo XIX, la frontera había simbolizado en los Estados Unidos el cambio social, la movilidad geográfica, el individualismo y la posibilidad de hacer realidad el sueño americano. Dos novelas tan diferentes como The Custom of the Country (Las costumbres nacionales) de Edith Wharton y O Pioneers! (Pioneros) de Willa Carter (ambas publicadas en 1913) coincidían al mostrar el poder transformador de la frontera en la cultura norteamericana, justo antes de los cambios sociales acaecidos tras el estallido de la Primera Guerra Mundial. Ambas novelas analizaban, desde puntos de vista diferentes, cómo la frontera había producido una serie de personajes que habían alterado completamente los valores sociales de los Estados Unidos. 
Tras la guerra, la frontera como símbolo de trasformación social había desparecido de manera radical. La cultura urbana lo invadía todo con sus potencialidades y, también, con sus limitaciones. En ciudades como Nueva York, los individuos tenían ahora que adaptarse a los ritmos de la cultura de masas y a un nuevo espacio material en el que el individuo ocupaba un lugar muy secundario. Algunas de las obras literarias más importantes de los años veinte, trataron de abordar ese problema. F. Scott Fitzgerald en su novela The Great Gatsby (El gran Gatsby, 1925) trató de retratar la fascinación que supone para muchos individuos la nueva realidad urbana. La historia de la decadencia y caída de Jay Gatsby, un sofisticado gánster que habita en Long Island, retrata una realidad urbana en la que abundan deslumbrantes coches y mansiones, enormes estaciones de trenes e innumerables rascacielos. Muestra la desbordante alegría orgiástica de una nueva cultura que se asimilaba a la de un parque de atracciones, y en la que no faltaban la violencia y el anonimato. La otra gran obra literaria relacionada con Nueva York es Manhattan Transfer (1925) de John Dos Passos. Al contrario que en la obra de Fitzgerald, en esta novela el protagonista no era un individuo, sino toda una ciudad. La estructura fragmentaria de esta obra, así como los elementos documentales de la misma, han hecho que se la compare a los experimentos cinematográficos realizados en esa época por Sergei Eisenstein y Dziga Vertov (Brogi 2012, p. 2; Foster 1986, pp.190-192; Suárez 1999, 50).

Dos Passos nos muestra cómo la ciudad de Nueva York se había convertido en una nueva Babilonia, en la que los individuos eran incapaces de apoderarse de sus propias vidas. La gran ciudad fragmentaba a las personas y los grupos humanos convirtiendo el paisaje urbano en un inmenso y anónimo tapiz.

A pesar de su pesimismo, tanto Dos Passos como Fitzgerald no podían ocultar en sus obras su fascinación por la técnica y la velocidad de la metrópolis, por sus cambios violentos, por sus colores y formas. La metrópolis era a la vez símbolo de progreso tecnológico y de regresión. Los incendios, las peleas, las borracheras, el miedo y la soledad acompañaban inexorablemente a la sofisticación de la cultura urbana. El mundo moderno no es retratado como un símbolo de progreso lineal y de liberación, sino como un universo deforme y accidental, en el que todo es impredecible y no hay nada seguro que no sea la muerte. No es de extrañar, que tanto Manhattan Transfer como The Great Gatsby mostraran en sus capítulos finales un fuerte nostalgia por los valores de la cultura de la frontera y del individualismo del siglo XIX. La imagen mítica de la frontera evocaba un tipo de sociedad en la que era aún posible la libertad y la conquista de un espacio propio. Sin embargo, a pesar de esto, en ambas obras la modernidad, encarnada en Nueva York, se retrataba como una fuerza ineluctable que se apoderaría de toda la cultura norteamericana.

\section{El cine ante Nueva York}

El cine de Hollywood en los años veinte no podía permanecer indiferente ante los retos y la fascinación de Nueva York (Dalle Vacche 2009, pp.219-220). En 1927 se rodaron en dicha ciudad una serie de películas en las que se buscó asimilar, la modernidad que significaba la gran ciudad, a la narrativa de Hollywood, basada principalmente en una serie 
de principios melodramáticos en los que el individuo representaba aún el núcleo de la historia. Entre las obras rodadas en Nueva York en ese año destacan The Crowd (El mundo marcha) de KingVidor, Speedy (Relámpago) de Ted Wilde y Lonesome (Soledad) de Paul Fejos. Las tres películas se estrenaron en 1928. Cada una de ellas buscó explorar los diferentes aspectos de la vida en la gran metrópolis, sin dejar de ocultar al espectador de la época los peligros de la gran ciudad así como todo lo que había de fascinante e innovador en Nueva York en esa la época.

El análisis conjunto de estas películas representa un importante instrumento a la hora de valorar cómo el cine ha tratado de adaptarse a la modernidad, sin abandonar completamente muchas estructuras del melodrama del siglo XIX. Cada una de estas obras se acerca a Nueva York, símbolo de ineluctable progreso y deshumanización, tratando de defender los valores tradicionales de la familia nuclear, la importancia de las emociones, de la amistad, del triunfo del bien sobre el mal. El resultado es un producto híbrido, en el que se intenta mostrar una realidad y ocultarla al mismo tiempo.

No en vano, a pesar de abordar temáticas diferentes, The Crowd, Speedy y Lonesome comparten muchos elementos. En primer lugar, cada una de estas películas trata de mostrar como los individuos se enfrentan a la nueva realidad urbana. Al contrario que en Manhattan Transfer de John Dos Passos en la que se muestra la ciudad como una enorme colmena, estas narrativas se centran en la vida de una pareja o familia. En segundo lugar, todas estas películas analizan la importancia del ocio en la gran ciudad. En todas ellas, aparece el parque de atracciones de Coney Island que simboliza el nuevo espacio urbano, en el que el individuo puede liberarse de los problemas cotidianos y ser feliz. Finalmente, en todas estas producciones de Hollywood se insiste que, a pesar del enorme poder de la gran ciudad, existe aún la posibilidad de que el individuo sea feliz y controle hasta cierto punto su propia vida.

\section{El enfrentamiento con la gran ciudad}

The Crowd, estrenada el tres de marzo de 1928, fue rodada en las calles de Nueva York. El rodaje buscaba acercar al espectador con el día a día en la gran metrópolis y con las vicisitudes de un individuo cualquiera a la hora de enfrentarse con los problemas que surgían en la nueva realidad (Durgnat y Simmon 1998, pp.79-80). King Vidor experimentó con la cámara y con los actores con el fin de obtener un nuevo realismo cinematográfico, muy lejano del cine de los ideales del cine de Hollywood de la época.

En el inicio de The Crowd, King Vidor analiza las enormes dificultades que tiene un individuo para llegar a realizar el sueño americano en el siglo XX. El nuevo espacio metropolitano se convierte en un enorme obstáculo y la ciudad se convierte en la película en una enorme jungla en la que el individuo se halla perdido y desorientado. El protagonista de la esta obra, John Sims (James Murray), llega a Nueva York con la esperanza de realizar sus sueños y destacar por encima de la multitud. Huérfano de padre, nacido el cuatro de julio de 1900, John simboliza la continuidad de los ideales románticos del siglo XIX en los inicios de un nuevo siglo. Ante la imagen de la Estatua de la Libertad, John Sims se retrata 
a sí mismo como un joven ambicioso que aspira como millones de ciudadanos de Nueva York a tener una oportunidad.

Tras esta imagen de Sims a su llegada a Nueva York, Vidor nos ofrece una serie de planos de la ciudad en la que se muestra la nueva realidad urbana a la que tiene que hacer frente el protagonista para lograr destacar y abrirse paso entre la multitud. Las primeras imágenes de Nueva York que aparecen en The Crowd, evocan a la ciudad laberíntica y caótica que aparece en Manhattan Transfer: enormes rascacielos amenazantes, miles de coches y figuras apresuradas de transeúntes.

Siguiendo el guion original de John V. A. Weaver, la cámara de Vidor nos conduce a una serie de rascacielos en el interior de cuyas ventanas aparecen series interminables de mesas, rostros humanos de oficinistas que, al final, no son más que números y nombres (Young 2014, pp.17-18). Uno de esos oficinistas es John Sims con el número 137. John Sims es un oficinista más, esperando terminar el trabajo para disfrutar de unos momentos de descanso y olvidarse de todo. Vidor retrata a la oficina moderna como un enorme mundo uniformado, una inmensa masa de seres humanos que han perdido el entusiasmo por la vida. Se limitan a ser una pieza más de un enorme engranaje, como si se tratara de los obreros que aparecen en Metropolis (Metrópolis, 1927) de Fritz Lang. Vidor nos muestra en The Crowd cómo la modernidad urbana ha ido desvaneciendo el sueño americano y todos sus ideales liberales. La modernidad ha domesticado a muchos hombres como John Sims, les ha convertido en seres anónimos.

De manera muy parecida a la película de Vidor, la obra de Ted Wilde Speedy comienza mostrando una visión panorámica de Nueva York, una ciudad dominada por rascacielos enormes, tráfico y prisas. Estrenada el 7 de abril de 1928, la película se rueda como The Crowd en las calles de la gran metrópolis (Lopate, 2015). Sin embargo, en Speedy se detalla la existencia de otro Nueva York, un Nueva York nostálgico que se resiste a ser apropiado por las oscuras fuerzas de la modernidad. Es la ciudad de Pop Dillon (Bert Woodruff). Pop es un conductor de un viejo tranvía tirado por caballos que se resiste a abrazar la modernidad. Pop no es un individuo solitario en la gran metrópolis como John Sims en la obra de Vidor. Pop tiene una nieta, Jane (Ann Christy), que está comprometida con Harold Swift (Harold Lloyd). Este trio tratará de luchar contra los intereses de las grandes empresas de trasportes de la ciudad que intentan apoderarse del tranvía. Speedy logra atraer al espectador de la época al evocar la nostalgia de un mundo romántico, ya casi desaparecido, y recrear la complejidad y el frenesí de la gran ciudad. El personaje principal, Harold Swift, representa a una nueva clase social proletaria apasionada por el deporte. La pasión por el baseball hace que Harold pierda su empleo en un drugstore, cuando se olvida de atender a los recados encomendados por su jefe y se recrea mirando en los escaparates de un negocio de apuestas las noticias procedentes del estadio.

Más tarde, cuando Harold Swift consigue un empleo como taxista, descubre la complejidad de la ciudad: lo difícil que resulta luchar contra el tráfico y las multas, los límites de la tecnología y la importancia del azar. A pesar de todo el romanticismo que rodea a un personaje que antepone el ocio al trabajo, Speedy muestra también lo difícil que resulta a un individuo desempañar su profesión en un mundo cambiante, controlado por la tecnología y el azar. Esa compleja realidad urbana, se transforma en una pesadilla para Harold Swift y 
su familia cuando una gran compañía de transportes quiere apoderarse del tranvía de Pop a cualquier precio, recurriendo al chantaje y a la fuerza. Speedy nos muestra los diferentes niveles de la modernidad: un mundo complejo controlado por la técnica y el capitalismo sin escrúpulos al que los individuos deben enfrentarse para sobrevivir.

Lonesome de Paul Fejos se acerca a Nueva York desde otra perspectiva. La película, estrenada el 30 de septiembre de 1928, es una de las últimas obras del cine mudo que trata de acercarse a la complejidad del mundo urbano con una gran originalidad estética y en la que la cámara se mueve con una enorme libertad, algo que ya no será posible con las imposiciones técnicas del cine sonoro (Lopate 2012). Como señala Malcolm Wood, el modernismo cinematográfico no es tan solo el producto de una serie de temas, sino también de una serie de estrategias estéticas que buscan sacar a la luz una nueva realidad, a través de una sintaxis basada en la acumulación y asociación de significados (p, 223). Esta nueva estética se pone de manifestó en obras como las de Fejos. En Lonesome los personajes principales son Jim (Glenn Tryon) y Mary (Barbara Kent). Jim trabaja en una fábrica; Mary es una telefonista. A través de un montaje paralelo y de la superposición de imágenes, el espectador contempla cómo es la vida cotidiana de ambos personajes en la gran ciudad. Una vida marcada por los horarios, las multitudes y las prisas. Los personajes no aspiran a nada, tan solo a sobrevivir en la gran ciudad. Son pocos sus momentos de ocio y de descanso.

El trabajo es, en efecto, el eje de sus vidas. Fuera del universo del trabajo les espera un apartamento solitario, nada más. La vida frenética en la ciudad produce un mundo sin esperanza, en la que los individuos viven aislados y se sienten incapaces de comunicarse espontáneamente con sus semejantes. Ante esa perspectiva, la única solución que propone la estructura melodramática de Hollywood es la de encontrar una pareja. La familia nuclear supone el último refugio ante un mundo deshumanizado. Lonesome muestra los intentos desesperados de Jim y Mary por encontrar otra persona con la que compartir la existencia y escapar, por unos instantes, a la deshumanización de la gran metrópolis.

\section{Coney Island: el último refugio}

The Crowd, Speedy y Lonesome muestran la función catártica de Coney Island. El enorme parque de atracciones construido a finales del siglo XIX constituye para muchos habitantes de Nueva York una vía de escape. No en vano, en cada una de estas obras, el parque de atracciones representa un motivo narrativo singular, un lugar de encuentro, alienación y reconocimiento.

En The Crowd el parque de atracciones de Coney Island es, ante todo, un lugar de reconocimiento. John Sims acude a él en compañía de su compañero de oficina Bert (Bert Roach) y de dos oficinistas, Jane (Estelle Clark) y Mary (Eleanor Boardman). El parque de atracciones con su montaña rusa, cervecerías y una enorme noria representa el lugar en el que son posibles la catarsis y el deseo, las risas y las sorpresas, todo aquello que sugiere la posibilidad de escapar momentáneamente a la rutina del trabajo. Es un espacio 
público, programado para la diversión, con sus tiempos y sus rituales. John y sus amigos llegan al parque de atracciones tras luchar por encontrar un espacio en el abarrotado tren urbano que les conduce al recinto. Allí, John descubre que se siente atraído por Mary, y que está será la mujer de su vida. Por la noche, cuando el grupo regresa a casa, se sienten cansados y fatigados. Vidor sugiere cómo la diversión programada es una continuación de la jornada de trabajo. Además, en el parque de atracciones y en los medios de transporte, los personajes se encuentran constantemente invadidos por los estímulos de la publicidad que tratan de apoderarse de sus vidas y de sus deseos. Vidor nos muestra que el espacio diseñado para la libertad y la diversión no es más que otra prisión sutil de la modernidad. En Speedy aparece también Coney Island como un lugar para la diversión y la catarsis. Como les ocurre también a los personajes de The Crowd, Harold y Jane se afanan por llegar al parque de atracciones tras abrirse paso entre la multitud que llena los trenes y tranvías. Ambas películas muestran que poder disfrutar de unos momentos de felicidad en la gran ciudad supone un esfuerzo y una lucha, no menos ardua que la que se requiere para triunfar en el trabajo. En Speedy, Coney Island simboliza, además, caos y control. La imagen de caos se construye narrativamente a través de las peripecias de Harold en el parque de atracciones. Trata de salir intacto de Coney Island con su traje nuevo, pero resulta del todo imposible. La realidad es demasiado compleja y cambiante para controlar algo tan aparentemente sencillo como un traje nuevo. Harold y Jane tampoco logran controlar su dinero. Las atracciones son tantas que se dejan arrastrar por sus encantos hasta quedarse sin dinero para comprar un billete de vuelta. Speedy muestra lo difícil que resulta controlar el paisaje urbano. Sin embargo, gracias a la solidaridad de un transportista amigo que se ofrece a montarlos en su camión de regreso a Nueva York, Harold y Jane logran regresar a casa tras una jornada llena de fatigas y de diversión.

Finalmente, Coney Island se convierte en un espacio de reconocimiento y alienación en Lonesome. Jim y Mary se conocen por casualidad en una de las playas de Coney Island después de que han acudido a la feria atraídos por la publicidad procedente de un vehículo que anunciaba las atracciones de la misma. En la feria, ambos personajes se despojan de su máscara. Los dos reconocen el uno al otro sus orígenes obreros, su soledad, sus vidas anónimas y sus miedos. Como los personajes de The Crowd, Jim y Mary se adentran en los rituales de las atracciones de la feria y descubren en ese lugar, lejano de la gran ciudad, su mutuo amor. La feria aparece retratada como un espacio público, en donde a pesar de su masificación y el constante ruido de sus atracciones, todavía se puede encontrar una común humanidad. Sin embargo, un incidente en una montaña rusa, obliga a que los amantes se separen, y cada uno volverá a su respectivo hogar sin saber nada del otro.

A pesar de la complejidad del lugar, en estas tres obras Coney Island representa un espacio público en el que las diferentes parejas se comprometen como tales y comienzan, también, a planificar su futuro conyugal. Es como si Fejos, Vidor y Wilde excluyeran el espontáneo reconocimiento del otro y la mirada hacia el futuro de la dura realidad de la metrópolis dominada por el trabajo y las prisas. 


\section{La resolución del conflicto}

Finalmente, a pesar de la fascinación y la complejidad alienante de la realidad urbana, cada una de estas películas se afana por preservar los valores del individuo y de la familia en su conclusión. Esto muestra cómo el cine de Hollywood trata, por un aparte, de acercar la modernidad al espectador, $y$, por otra parte, se afana por defender los valores tradicionales del siglo XIX.

En The Crowd, King Vidor muestra cómo, al final de la película, John y Mary logran sobrevivir al horror y el caos de la gran ciudad refugiándose en un teatro, acompañados de su hijo Junior (Freddi Burke Frederick). Tras ver cómo muchos de sus sueños se han convertido en cenizas, especialmente después de la muerte de su hija (Alice Mildred Puter), tras ser atropellada por un coche en las calles de Nueva York, la familia encuentra un momento de catarsis rodeada de una anónima multitud. John ya no trabaja como oficinista. Ha perdido su trabajo al ser incapaz de adaptarse al ritmo de la oficina después de la muerte de su hija. Tras realizar innumerables trabajos, ha encontrado un trabajo como hombre anuncio. En el teatro, rodeado por sus seres queridos, se identifica con las atracciones. Sonríe con la multitud. Ha renunciado a sus sueños. Se limita a ser un mero superviviente en la gran metrópolis. Vidor nos muestra la imagen del teatro, de los innumerables rostros que sonríen y patalean como la de una enorme colmena escondida en una caverna. La gran ciudad ha devorado a la familia Sims, pero han sabido conservar su dignidad. Reconocen también esa dignidad en los otros. Es un final muy complejo ideológicamente, en el que no se renuncia completamente al sueño americano, pero se reconocen sus límites.

En Speedy, el personaje interpretado por Harold Lloyd, logra ayudar a su familia y que la compañía de transportes se apropie del viejo tranvía tras pagar un precio justo. El final feliz se alcanza tras una larga serie de vicisitudes que muestran la complejidad de la vida en Nueva York y cómo el cine de Hollywood quiere preservar los valores tradicionales de la sociedad norteamericana y mostrar, al mismo tiempo, lo inexorable realidad del progreso vinculado al mundo capitalista.

El final de Speedy trata de mostrar, por otra parte, que se pueden preservar los viejos valores en el contexto urbano. Harold consigue recuperar el tranvía, que había sido secuestrado por una serie de rufianes pagados por la compañía de trasportes. El tranvía regresa a las calles de su barrio y logra respetar las ordenanzas municipales. El municipio permitía que Pop conservara la licencia de trasporte, siempre y cuando el tranvía estuviera en funcionamiento al menos una vez cada veinticuatro horas. Gracias a una curiosa serie de accidentes y casualidades favorables, Harold logra apropiarse del espacio urbano y conducir el tranvía de una punta de la ciudad a otra, tras una persecución frenética y logrando esquivar a la policía. Speedy nos muestra un paisaje urbano dominado por el azar y la necesidad, al que deben adaptarse los individuos para sobrevivir. Si una serie de circunstancias desfavorables habían hecho que Harold perdiera su trabajo como taxista, ahora, otra serie de circunstancias favorables le habían ayudado a recuperar el tranvía y hacer que esté siguiera en funcionamiento. El triunfo de Harold hace que la compañía de trasportes acepte los cien mil dólares que éste pide por la concesión de la licencia del tranvía. 
El final de Lonesome no es menos esperanzador que el de Speedy. Tras haber perdido a Mary en Long Island, Jim regresa a su apartamento de Nueva York. Se encuentra solo y desesperado. El parque de atracciones le ha mostrado la posibilidad de la felicidad. Sin embargo, el azar le ha alejado para siempre de alcanzar esa posibilidad vital. Desesperado, Jim hace sonar el disco "Always" en su apartamento. La música suena con tanta intensidad que molesta a la persona que habita en otra habitación contigua. Esa persona es Mary, que comienza a golpear la pared. En pocos minutos, los amantes vuelven a encontrarse por una casualidad del destino. Habían vivido uno al lado del otro durante meses y nunca habían tenido tiempo para hablar espontáneamente y conocerse dominados por los ritmos asfixiantes del trabajo en un mundo urbano. La obra de Fejos termina con el encuentro inesperado de Jim y Mary, con la posibilidad del amor en un mundo anónimo y deshumanizado.

\section{Conclusión}

En The Crowd, Speedy y Lonesome el cine de Hollywood trató de aproximarse a la complejidad y los restos de Nueva York, como símbolo de la modernidad, tratando de preservar una estructura narrativa melodramática que resultase atractiva al público de la época. Cada una de estas obras logró sacar a la luz las vicisitudes de miles de individuos atrapados en la realidad urbana y cómo esta realidad puede llegar a ser controlada, pero solo hasta cierto punto. Así, en The Crowd, el núcleo familiar consigue tan solo sobrevivir y reconocerse como parte de la multitud tras renunciar a muchos de sus sueños. El personaje de Harold logra triunfar al final de Speedy al conseguir que la compañía de trasportes acepte su oferta. Sin embargo, a pesar de eso, el mundo y los valores del siglo XIX asociados al tranvía guiado por caballos desaparece para siempre del universo de la ciudad. Además, las compañías de trasportes, controladas por hombres sin escrúpulos, parecen dominar el futuro de la ciudad. Finalmente, a pesar de que Jim y Mary puedan vivir juntos en Lonesome, tras haberse perdido entre la multitud, la realidad urbana que rodea a sus vidas sigue marcada por el trabajo, la fatiga y el control social. El amor representa tan solo una tregua. Como conclusión, estas tres películas estrenadas en 1928, coinciden en su descripción de la ciudad con la de otras obras literarias modernistas: The Great Gatsby y Manhattan Transfer. Sin traicionar las expectativas del espectador de Hollywood acostumbrado a los finales felices y al triunfo del individuo, The Crowd, Speedy y Lonesome sacan a la luz una realidad urbana dominada por el azar, en la que todo parece ser accidental. Nueva York es un universo caótico, en perpetuo movimiento, angustioso y claustrofóbico. En esa nueva realidad controlada por el azar, los individuos no pueden aspirar a ser más que sobrevivientes.

A pesar de la estructura melodramática presente en estas obras, la cual sigue dando primacía al individuo por encima de la colectividad, ninguna de estas películas ignora que la nueva realidad urbana representa un enorme reto. Todas señalan los riesgos del progreso, y que el triunfo de la técnica no consigue hacer que los individuos se adueñen de su propio espacio inmediato. Estas obras anuncian muchos de los temas que aparecerán en la década de los cuarenta con la irrupción del cine noir, en las que el sueño americano se habrá transformado en un universo de pesadilla y azar. 


\title{
Lista de Referencias Bibliográficas
}

Bradbury, M. (1991) “The Cities of Modernism”. Modernism: A Guide to European Literature. 1890-1930. Bradbury, M. and McFarlane, J. (Eds.). New York and London: Penguin Books, pp. 96-104.

Brogi, D. (2012). "Modernismo Antiborghese. Manhattan Transfer Di John Dos Passos." Le Parole e Le Cose. Disponible en: www.leparoleelecose.it/? $\mathrm{p}=6791$.

Dalle Vacche, A. (2009). “1928: Movies, Social Conformity and Imminent Traumas.” American Cinema of the 1920s: Themes and Variations. Lucy Fischer (Ed.). New Brunswick New Jersey, London: Rutgers University Press, pp. 211-233.

Durgnat, R. y Simmon, S. (1988). King Vidor, American. Berkeley: University of California Press.

Foster, G. (1986). "John Dos Passos' Use of Film Technique in 'Manhattan Transfer \& The 42nd Parallel”. Literature/Film Quarterly, vol. 14, no. 3, pp. 186-194.

Lopate, P. (2015). “Speedy: The Comic Figure of the Average Man." The Criterion Collection Disponible en: www.criterion.com/current/posts/3826-speedy-the-comic-figure-of-theaverage-man.

Lopate, P. (2012). “Lonesome: Great City, Great Solitude.” The Criterion Collection, Disponible en: www.criterion.com/current/posts/2436-lonesome-great-city-great-solitude.

Suárez, J. A. (1999). "John Dos Passos's USA and Left Documentary Film in the 1930s: The Cultural Politics of 'Newsreel' and 'The Camera Eye"'. American Studies in Scandinavia, vol. 31, no. 1, pp. 43-67.

Young J. R. (2014). King Vidor's The Crowd: the Making of a Silent Classic, Forward by Kevin Brownlow. Past Times Publishing Co.

Wood, M. (2011). "Modernism and Film". The Cambridge Companion to Modernism. M. Levenson (Ed.). Cambridge: Cambridge University Press, pp. 217- 232.

\begin{abstract}
Through the analysis King Vidor's The Crowd, Ted Wilde's Speedy, Paul Fejos' Lonesome, all of then shot in New York, this work explores the emergency of that city as a paradigm of modern metropolis in the 1920s. In particular, this study seeks to cast light on how the classical Hollywood narrative faced the challenges stemming from the modern metropolis celebrating the power of the average individual against a context dominated by mass culture.
\end{abstract}

Keywords: John Dos Passos- Paul Fejos - F.S. Fitzgerald- Harold Lloyd - King Vidor

Resumo: Este trabalho visa compreender a importância que adquire Nova Iorque como um paradigma da cidade moderna, na década de 1920 através da análise de uma série de filmes rodados na cidade durante a década de 1920, incluindo obras como The Crowd de King Vidor, Speedy de Ted Wilde e Lonesome de Paul Fejos. 
Palavras chave: John Dos Passos- Paul Fejos - F.S. Fitzgerald- Harold Lloyd - King Vidor - Cidade moderna - filmes década 1920

[Las traducciones de los abstracts fueron supervisadas por el autor de cada artículo] 